\title{
QUANTIFICAÇÃO DO DESFLORESTAMENTO NO MUNICÍPIO DE CANAÃ DOS CARAJÁS COM O USO DE GEOTECNOLOGIA EM ANÁLISE MULTITEMPORAL
}

\author{
Hilquias Miranda Cortez; Samy Cardoso Sá; Antônio Pereira Júnior \\ DOI: $10.4322 / 978-85-455202-1-4-02$ \\ INTRODUÇÃO
}

A Amazônia Legal Brasileira é uma área de alta importância a níveis nacionais e globais, a biodiversidade nesse bioma é tão rica que o caracteriza como um dos maiores bancos genéticos do planeta, porém, o avanço da fronteira urbana e agrícola causou e vem causando a perda de uma considerável área através do desflorestamento voltado para agricultura, pecuária, ocupação e obtenção de matéria prima para a indústria (FERREIRA et al., 2005).

A problemática do desflorestamento na Amazônia tem suas raízes na própria ocupação do país, entretanto, o crescimento e a intensificação deste se deu através da implementação de políticas públicas federais no início da década de 70, de fato, estas políticas foram tão decisivas que após estes incentivos os índices de desflorestamento na Amazônia legal subiram drasticamente (SOARES FILHO et al., 2008).

Estas políticas proporcionaram também a criação de programas nacionais de monitoramento que utilizam geotecnologia como ferramentas de ação, assim como a implementação destes recursos e o desenvolvimento de um Sistema de Informação Geográficas, estes programas marcaram o início do uso das geotecnologias no cenário nacional (SOUSA, 2011).

Quanto a isso, o desenvolvimento de geotecnologias como ferramenta para o controle do avanço da fronteira agrícola e rural no país reflete a preocupação com o desflorestamento, e tem sido amplamente utilizada em pesquisas e trabalhos realizados com este objetivo, já que os primeiros dados de imagens de satélite disponíveis são representações de um período posterior à implementação dos grandes projetos, mas que ainda carregam as consequências do mesmo, através da ocupação da terra e o consequente desflorestamento da mata nativa (LIMA, 2011)

Logo, quando o assunto é desflorestamento, vale a pena ressaltar que, dentre os estados brasileiros que fazem parte da Amazônia Legal, o Pará apresenta os maiores índices de desflorestamento, alcançando em anos de pico, como em 1995, valores que se aproximavam dos $30.000 \mathrm{~km}^{2} / \mathrm{ano}$, este fato tem relação direta com os grandes projetos na Amazônia Legal Brasileira, principalmente após a construção da Rodovia Federal Belém-Brasília, que possibilitou um grande êxodo para a região, intensificando assim a supressão à cobertura vegetal (FEARNSIDE, 2005).

Em função disso, os estudo que envolvem a geotecnologia e a ocupação de terras no estado, essa ferramenta é utilizada para a mensuração do desflorestamento, dada a relevância deste tipo de estudo, aliando este estudo ao banco de dados disponíveis é possível traçar o avanço dentro de um dado intervalo de tempo, possibilitando a visualização da progressão da supressão florestal quantificando assim os aumentos nos índices sofridos por um munícipio, uma cidade ou uma área e estabelecer a partir destes e de uma série de outros levantamentos estudos direcionados à área de interesse da pesquisa (CARVALHO et al., 2000).

O município de Canaã dos Carajás se enquadra dentro desta situação, pois se originou de um projeto de assentamento (PA), resultado dos grandes projetos na Amazônia Legal Brasileira. Desta forma a escolha do estudo a respeito do desflorestamento no município mostra-se de grande importância para a percepção da magnitude da perda de área verde, da metodologia de gerenciamento com a aplicação das tecnologias atualmente disponíveis como incrementos aos processos de fiscalização e controle dessas ações que apresentam um grande montante de impactos ambientais negativos. 
Enfim, os desflorestamentos continuam, e isso justificou esta pesquisa e incrementou a relevância da mesma, pois, ela mostra dados em análise multitemporal dessas ações, e isso contribuiu para que o objetivo quanto a análise da perda florestal, em $\mathrm{km}^{2}$, da área total município de Canaã dos Carajás, dos intervalos quadrienais (1984 a 2012) entre a primeira (1984) e a última imagem (2012)

\section{REFERENCIAL TEÓRICO}

\section{O DESFLORESTAMENTO E A OCUPAÇÃO NA AMAZÔNIA}

A região correspondente à Amazônia legal Brasileira é uma área que engloba os estados do Acre, Amapá, Amazonas, Maranhão, Mato Grosso, Pará, Rondônia, Roraima e Tocantins, esta é de grande relevância para o país, pois essa área ocupa o correspondente a $60 \%$ território brasileiro, e o equivalente à aproximadamente $6.811 .900 \mathrm{Km}^{2}$, nela se encontra o maior manancial de água doce do mundo, a Bacia Amazônica e ainda a Bacia Tocantins-Araguaia, somando em toda a região 1/5 das reservas mundiais de água doce, sendo as atividades antrópicas que mais geram redução de cobertura vegetal a pecuária e a atividade madeireira, através de queimadas, criação de pastagens e derrubada de árvores para comercialização (BRASIL, 2003).

A busca pelo desenvolvimento apresenta uma linha muito tênue com as causas ambientais, pois essas complicações já ocorriam inclusive na extração e comércio do Pau-Brasil pelo seu reconhecido valor econômico, entretanto, este processo extrativista da madeira ocorreu na região amazônica até a década de 50 e não apresentava valores tão significativos, devido à localização ser, principalmente, em regiões litorâneas e em faixas de terra ribeirinhas que estavam incluídas na navegação, já que as primeiras frentes de exploração ocorreram durante as décadas de 20 e 30 , ainda com baixa expressão de desflorestamento (VALERIANO et al., 2012).

Os percussores da intensificação da atividade madeireira na Amazônia legal foram as políticas públicas de ocupação federais iniciadas na década de 70 durante a ditadura militar, principalmente as políticas do "Integrar para não Entregar" e "Terra sem Homem para Homem sem Terra", discurso feito pelo presidente Médici onde foi realizada a entrega de terras, sendo também nessa década realizados os primeiros levantamentos do Instituto Nacional de Pesquisas Espaciais (INPE) sobre os desflorestamentos na Amazônia (OLIVEIRA,1994).

Contudo, foi apenas na década de 80 que o avanço crescente de áreas desflorestadas passou a preocupar o governo federal devido às novas discussões ambientais internacionais, em 1988, o governo brasileiro solicitou um sistema de monitoramento anual ao Instituto Nacional de Pesquisas Espaciais (INPE) para responder à pressão internacional e se preparar para a Conferência Eco-92, o resultado foi a criação do Projeto de Monitoramento do Desmatamento da Amazônia Legal por Satélite (PRODES). Estima-se que durante os quase cinco séculos antecedentes à década de 70, a presença europeia desmatou uma área "ligeiramente maior que Portugal" (SILVA, 2010).

Porém, as discussões políticas em relação ao agravamento do desflorestamento na região da Amazônia Legal Brasileira iniciaram-se em 2000, pelo Ministério do Meio Ambiente (MMA) com apoio do Banco Mundial, para o acompanhamento do aumento de área desflorestada foram usados dados do INPE que permitiam acompanhar o crescimento do fenômeno, mas não permitiam a formação de políticas interventivas, muito se discutiu a respeito, principalmente em relação a atividades de agropecuária e madeireira, e foram propostos estudos sobre as condicionantes econômicas, culturais e financeiras que regiam o crescimento do desflorestamento (BRASIL, 2003).

Todavia, esta discussão é ainda hoje bastante presente, já que, pela rentabilidade oferecida pelos processos desflorestadores, as causas ambientais encontram barreiras ideológicas impostas pelas vantagens financeiras, o que ocorreu, sobretudo, foi uma redução nos índices de desflorestamento a partir de 2007, alcançando em 2010 e 2011 índices ainda menores que os valores do início da década de 90 . Os valores referentes às taxas anuais de Desflorestamento variaram entre 1988 e 2012 (Figura 1). 
Figura 1 - Taxa de desflorestamento Anual da Amazônia Legal entre 1988 e 2012.

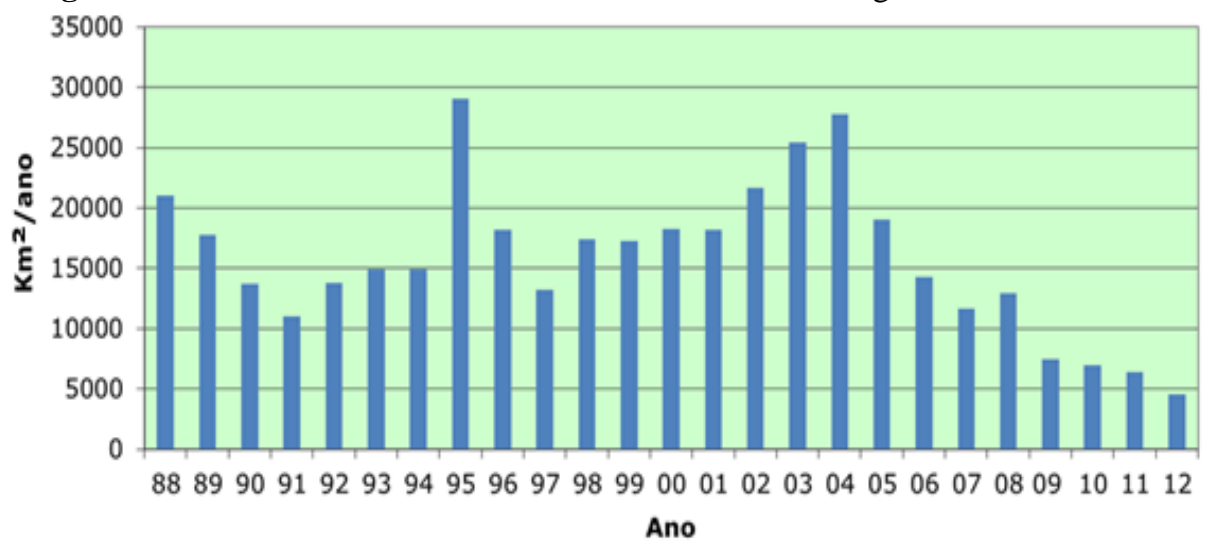

Fonte: INPE (2013).

Todavia, é necessário ressaltar que este pico em 95 poderia ser uma consequência da recuperação do plano real, instituído por Collor de Mello, então presidente da República, e da recessão econômica brasileira ocorrida no início da década, o objetivo da publicação do banco mundial sobre as causas de desflorestamento era suscitar as discussões sobre a relevância da implementação de técnicas de manejo ambiental com o propósito de conscientizar os agentes desflorestadores da importância e da irreversibilidade da perda de biodiversidade (FEARNSIDE, 2005).

A fim de desacelerar o avanço do desflorestamento, foram implementadas políticas, legislações e multas, além de campanhas federais que acompanhavam as conclusões anuais divulgadas pelo INPE, porém, a primeira ação significativa para a repressão do desflorestamento ocorreu em 1989, foi o chamado Programa Nossa Natureza, que em seguida apresentou variações nos índices de desflorestamento, positiva ou negativamente, independente das multas e programas implementados (RODRIGUES, 2004)

Este quadro mudou em 2000, principalmente pela proibição das queimadas, em Julho do mesmo ano, e pelo Programa de Licenciamento e Desmatamento, implantando no Mato Grosso pela Fundação Estadual do Meio Ambiente do Mato Grosso (FEMA), funcional entre 1999 e 2001, os estudos do INPE através das imagens de Advanced Very High Resolution Radiometer (AVHRR) em português, Radiômetro Avançado de Resolução Muito Alta, apontaram uma queda de $80 \%$ nas queimadas (FEARNSIDE, 2005).

A vegetação tem função importante através da evapotranspiração e da retenção de umidade da água no solo na diminuição da amplitude da temperatura do ar, mas as funções da vegetação são bem extensas e abrangem também a precipitação e o microclima regionais. O avanço das fronteiras urbanas e agrícolas acaba por invadir áreas de floresta nativa, intervindo no ecossistema e desflorestando a cobertura vegetal, responsável por manter as propriedades e características do solo, a perda destes fatores implica em adversidades ambientais (VILELLA, 2009).

O nível local é o primeiro a sofrer os efeitos do desflorestamento. A comunidade local recebe benefícios diretos e indiretos do equilíbrio de ecossistema florestal, e com a quebra deste equilíbrio, uma série de efeitos é desencadeada. A floresta serve como uma "esponja", isso significa que ela retém águas pluviais através de fenômenos naturais como a absorção, a adsorção e a própria retenção de águas nas folhas e galhos das árvores, além de acrescentar umidade localmente através da transpiração da água nas folhas, perder estas e outras atividades implica em alterar o ciclo hidrológico local, e as consequências podem variar entre os extremos, secas e inundações, que passam a atingir a comunidade que se beneficiava da floresta (BUTLER, s/d). Adiante serão discutidos individualmente os impactos de maior relevância condizentes com os fatores estudados. 


\section{ALTERAÇÕES NO CICLO HIDROLÓGICO E NO MICROCLIMA}

O desflorestamento também tem como consequência a interferência no ciclo hidrológico, no microclima e nas relações climáticas com outros países, regiões e dentro das bordas da bacia, à exemplo, a diminuição de chuvas no Sudeste brasileiro (SOARES FILHO et al., 2005).

Em um estudo de caso realizado em Rondônia foram analisadas as modificações microclimáticas, no fluxo de superfície e dos elementos climáticos, provocadas pelo desflorestamento da região amazônica, mais especificamente na região do Ji-Paraná em Roraima, em dois meses, um mês de seca (setembro) e um mês tipicamente úmido (janeiro). Neste estudo foram identificados como consequências climáticas provocadas pelo desflorestamento: a redução no saldo de radiação de ondas curtas e totais; aumento da temperatura do ar média do ar; uma pequena redução na umidade específica do ar; aumento na velocidade dos ventos; redução de valores de evaporação e precipitação e períodos de seca prolongados (FISCH et al., 1997).

Estes fatores são, segundo os autores, coerentes com observações já feitas em estudos sobre a distribuição regional da precipitação para a área sudoeste Amazônica, e também com as descrições sobre a convecção sudeste/noroeste da convecção amazônica (FIGUEIROA; NOBRE,1990; HOREL et al., 1989).

\section{ALTERAÇÕES NO SOLO}

Diversos problemas decorrem do desflorestamento, o solo sofre devido o avanço das fronteiras agrícolas e urbanas, tem-se a savanização de paisagens, algo preocupante, já que, por natureza, o solo amazônico é pobre em nutrientes e apresenta caráter ácido; a erosão e a compactação do solo, que passam a ocorrer de forma acelerada, não deixando tempo para o solo se regenerar e causa assoreamento de cursos e corpos d'água e a exaustão de nutrientes, provocando perda de qualidade do solo e redução de produtividade agrícola, prejudicando a manutenção da fertilidade (ABDON, 2004).

\section{GEOTECNOLOGIA}

Geotecnologia é a tecnologia utilizada para coleta, processamento, analise e exposição de informação com referência geográfica, sendo alguns exemplos (ROSA, 2005):

- $\quad$ Sistema de informação geográfica.

- Cartografia digital.

- Sensoriamento remoto.

- $\quad$ Sistema de posicionamento global (ou GPS, do Inglês Global Positioning System).

- Topografia georreferenciada.

A grande extensão territorial brasileira, aliada à dinâmica espaço temporal da atividade antrópica, torna difícil a obtenção de informações geográficas atualizadas e confiáveis. As geotecnologias podem auxiliar a obtenção dessas informações de forma mais rápida, precisa e com menor custo, quando comparadas às geradas pelas técnicas subjetivas tradicionalmente utilizadas (RIZZI, 2005).

\section{SISTEMAS DE INFORMAÇÕES GEOGRÁFICAS}

Sistema de Informação Geográfica (SIG ou GIS, do inglês Geographic Information System) são as ferramentas computacionais para o geoprocessamento e é, basicamente, um sistema que permite capturar, manipular, analisar e apresentar dados geograficamente referenciados (MONTANHER, 2008). 
O SIG em muitos casos é confundido com geoprocessamento, que é o conceito mais abrangente e representa qualquer tipo de processamento de dados georreferenciados, enquanto um SIG processa dados gráficos com ênfase em análises espaciais e modelagens de superfícies, ou seja, é uma técnica de geoprocessamento, sendo que nem todo geoprocessamento é um SIG (CARVALHO et al., 2000; GIROTTO, 2011).

O uso de $S I G$ traz enormes benefícios devido à sua capacidade de manipular informação espacial e, atualmente, os mais variados profissionais o utilizam para as mais variadas aplicações. Há pelo menos três grandes maneiras de utilizar um SIG (CÂMARA:DAVIS: MONTEIRO, 2001):

- $\quad$ Ferramenta para produção de mapas.

- Suporte para análise espacial de fenômenos.

- $\quad$ Banco de dados geográficos.

A maioria dos $S I G$ 's possuem funcionalidades básicas em comum, sendo que se diferenciam em função de sua operacionalidade e finalidades. (MONTANHER, 2008). O GIS contempla basicamente quatro funcionalidades (ROSA, 2005):

- $\quad$ Coleta, padronização, entrada e validação de dados.

- Armazenamento e recuperação dos dados.

- $\quad$ Análise e geração de informação.

- Saída e apresentação de resultados.

\section{BREVE HISTÓRICO DO SIG}

As primeiras tentativas de automatizar parte do processamento de dados com características espaciais aconteceram na Inglaterra e nos Estados Unidos, nos anos 50, mas os primeiros SIG surgiram na década de 60, no Canadá, como parte de um programa governamental, sendo os computadores necessários excessivamente caros, e a mão de obra tinha que ser altamente especializada e caríssima (MATIAS, 2001).

Ao longo dos anos 70 foram desenvolvidos novos e mais acessíveis recursos de hardware, tornando viável o desenvolvimento de sistemas comerciais. Foi então que a expressão Geographic Information System foi criada. Apenas grandes organizações tinham acesso à tecnologia (FERREIRA, 2006).

A década de 80 representa o momento quando a tecnologia de $S I G$ inicia um período de acelerado crescimento que culmina até os dias de hoje.

Ainda na década de 80, a introdução do Geoprocessamento no Brasil inicia-se a partir do esforço de divulgação e formação de pessoal feito pelo prof. Jorge Xavier da Silva (UFRJ) (CÂMARA: DAVIS: MONTEIRO, 2001). Em 1984, foi criada a Divisão de Processamento de Imagens (DPI) que é, atualmente, parte da Coordenação Geral de Observação da Terra (OBT) do Instituto Nacional de Pesquisas Espaciais (INPE), com a missão inicial de estudar e desenvolver soluções tecnológicas nacionais para tratamento de imagens de sensoriamento remoto (FELGUEIRAS, 2006).

\section{MATERIAL E MÉTODOS}

A metodologia empregada foi da observação sistemática, pois foi planejada com ações controladas, predeterminadas nos objetivos e propósitos do presente estudo (PRESTES, 2003).

Dessa forma, aplicou-se a metodologia em 5 (cinco) etapas distintas:

Etapa 1: consultas a teses, monografias, revistas, artigos e periódicos para elaboração do referencial teórico e apresentação do contexto do município e as políticas púbicas.

Etapa 2: Aquisição de imagens do satélite LANDSAT, disponibilizadas gratuitamente pelo INPE. Os limites do município não estão contidos em apenas uma zona de imagens, para abranger toda a sua área foram adquiridas as imagens das zonas 223-065, 224-064 e 224-065 (Tabela 1). Essas 
imagens foram baixadas em forma de banda que posteriormente foram utilizadas na composição da imagem raster.

Tabela 1 - Características das imagens utilizadas.

\begin{tabular}{lllll}
\hline Ano & Orbita & Banda & Satélite & Data da Imagem \\
\hline \multirow{2}{*}{1984} & $223-65$ & 3,4 e 5 & LANDSAT 5 & $27 / 07 / 1984$ \\
& $224-64 / 65$ & & & $16 / 06 / 1984$ \\
1988 & $223-65$ & 3,4 e 5 & LANDSAT 5 & $07 / 08 / 1988$ \\
& $224-64 / 65$ & & & $14 / 08 / 1988$ \\
1992 & $223-65$ & 3,4 e 5 & LANDSAT 5 & $02 / 08 / 1992$ \\
& $224-64 / 65$ & & & $22 / 06 / 1992$ \\
1996 & $223-65$ & 3,4 e 5 & LANDSAT 5 & $28 / 07 / 1996$ \\
& $224-64 / 65$ & & & $17 / 06 / 1996$ \\
2000 & $223-65$ & 3,4 e 5 & LANDSAT 5 & $12 / 06 / 2000$ \\
& $224-64 / 65$ & & & \\
2004 & $223-65$ & 3,4 e 5 & LANDSAT 5 & $25 / 07 / 2004$ \\
& $224-64 / 65$ & & & $29 / 07 / 2008$ \\
2008 & $223-65$ & 3,4 e 5 & LANDSAT 5 & $21 / 08 / 2008$ \\
& $224-64 / 65$ & & & $06 / 08 / 2012$ \\
2012 & $223-65$ & 3,4 e 5 & LANDSAT 5 & $04 / 09 / 2012$ \\
\hline
\end{tabular}

Elaborada a partir de dados coletados em links especializados.

Etapa 3: Utilização do software Quantum GIS 1.8 para:

a) Compor bandas e criar um mosaico quadrienal com as imagens obtidas $(1984,1988,1992$, 1996, 2000, 2004, 2008 e 2012), de forma a abranger o limite territorial do município de Canaã dos Carajás.

b) Vetorizar, em forma de polígonos, as áreas atingidas pelo desflorestamento dentro da área do município em cada uma das imagens selecionadas e, em seguida, calcular a área total de desflorestamento no município, utilizando, em ambos os casos, as ferramentas disponibilizadas pelo software QGIS como criação de camadas do tipo vetor, compositor de mosaicos e a calculadora de campo. Ressalta-se que a definição do método foi desenvolvida através de consenso mutuo dos elaboradores do trabalho após observações, tentativas e necessidades surgidas no decorrer da elaboração.

Etapa 4: Interpretação de dados, onde foi feito um acompanhamento da área desflorestada no município no decorrer dos anos (1988 a 2012), para possibilitar a visualização do acréscimo de área desflorestada e o avanço das fronteiras urbanas e agrícolas.

Etapa 5: Desenvolvimento de Tabelas, mapas temáticos e outros recursos visuais, de modo a facilitar a exposição de dados, dinamizar a apresentação interpretação e discussão dos mesmos nesse trabalho.

O projeto Quantum GIS (QGIS) foi iniciado oficialmente em maio de 2002, quando Gary Sherman começou a procurar um visualizador GIS rápido para Linux e com ampla gama de armazenamentos de dados. Isso, juntamente com um interesse na codificação de um aplicativo GIS, levou à criação do projeto. QGIS é um SIG que funciona em sistemas operacionais Linux, Unix, MacOsX e Windows, suporta variadíssimos tipos de dados, quer vectoriais, quer matriciais. Devido ao seu código de programação aberto, possui uma comunidade de utilizadores/desenvolvedores muito ativa que permite ciclos curtos de saída de novas versões e uma eliminação de erros de programação muito rápida, além de ter Licença Pública (PINTO, 2012).

O aspecto mais fundamental dos dados tratados em um SIG é a natureza da informação, visto que possuem duas componentes distintas. Por isso tão importante quanto localizá-los é descobrir e representar as relações entre os diversos dados no tratamento realizado. Os dados possuem informações (CARVALHO et al., 2000):

Gráfica: Possui a finalidade de descrever as feições locacionais e interações espaciais entre essas feições, tal qual um mapa. 
Alfanumérica: Representa as características, qualidades ou relacionamento de feições da representação gráfica. Geralmente são representadas em forma de Tabelas.

Existem duas formas principais de representar os dados, ambos surgiram da necessidade de estruturação de dados gráficos, possuindo vantagens e desvantagens de acordo com a destinação necessária, sendo que a maioria dos $S I G$ 's suportam ambas as representações. As formas principais são (CÂMARA; DAVIS; MONTEIRO, 2001).

Tentativa de reproduzir um elemento ou objeto o mais exatamente possível. Qualquer entidade ou elemento gráfico de um mapa é reduzido a três formas básicas: pontos, linhas, áreas ou polígonos (Figura 2).

Figura 2 - Exemplo de representação vetorial.

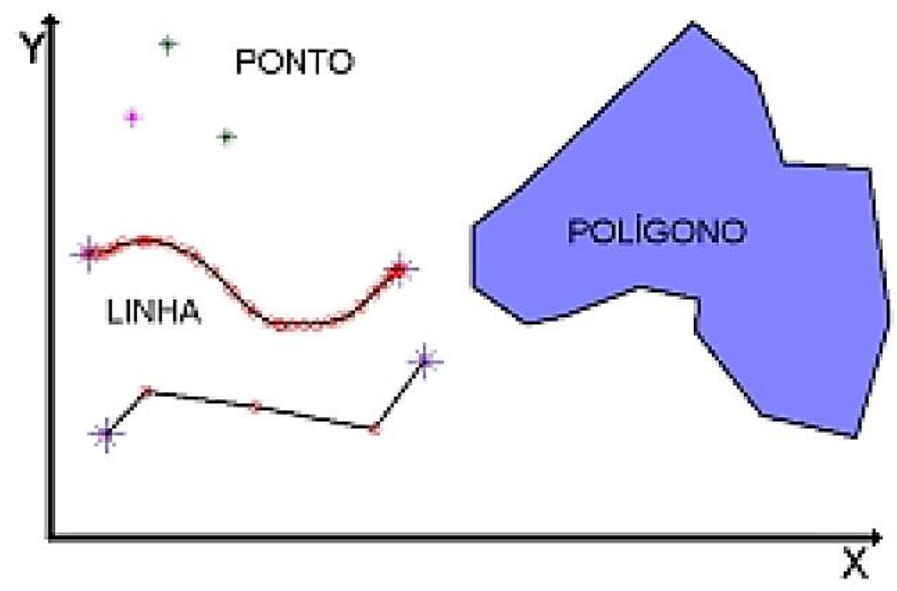

Fonte: Câmara: Davis: Monteiro (2001)

No modelo vetorial, a localização e a aparência gráfica de cada objeto são representadas por um ou mais pares de coordenadas com atribuições relacionadas a cada tipo de elemento que representa. Este tipo de representação é comum em sistemas de Desenho Assistido por Computador (ou CAD, do inglês, Computer Aidded Design) e outros tipos de sistemas gráficos porque o modelo vetorial é bastante intuitivo, embora nem sempre tais programas utilizem sistemas de coordenadas ajustados à superfície da Terra para realizar seus projetos

Na representação matricial o espaço é como uma matriz $\mathrm{P}(\mathrm{m}, \mathrm{n})$ composto de $m$ colunas e $n$ linhas, onde cada célula possui um número de linha, um número de coluna e um valor correspondente ao atributo estudado e cada célula é individualmente acessada pelas suas coordenadas. A resolução do sistema é dada pela relação entre o tamanho da célula no mapa e a área por ela coberta no terreno (Figura 3).

Figura 3 - Exemplo de representação matricial.

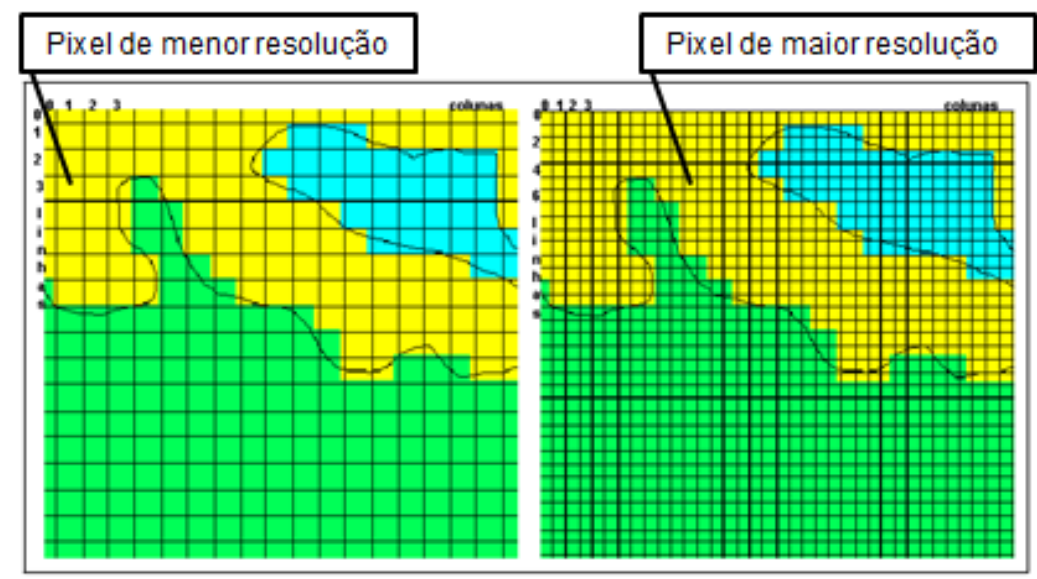

Fonte: Câmara, Davis, Monteiro (2001). 
Para a produção de cartas e em operações onde se requer maior precisão, a representação vetorial é mais adequada. As operações de álgebra de mapas são mais facilmente realizadas no formato matricial. No entanto, para um mesmo grau de precisão, o espaço de armazenamento requerido por uma representação matricial é substancialmente maior (CÂMARA et al., 2001).

De modo geral, é o objetivo o estudo que define a representação de dados: se a necessidade for acerca da distribuição e relação espacial de objetos então a representação vetorial é indicada. Se a necessidade for o estudo da variabilidade espacial, então a representação matricial é indicada (CARVALHO et al., 2000). Como métodos orientados à objetos, vetores e matrizes podem ser utilizados de forma simultânea, pois tratam elementos espaciais como objetos únicos (RIZZI, 2005). Porém em ambos, há vantagens e desvantagens (Tabela 2).

Tabela 2 - Vantagens e desvantagens das representações de dados. Continua...

\begin{tabular}{llll}
\hline TIPO & \multicolumn{1}{c}{ VETORIAL } & \multicolumn{1}{c}{ MATRICIAL } \\
\hline \multirow{3}{*}{ VANTAGENS } & $\bullet$ Estrutura compacta. & $\bullet$ Estrutura simples. \\
& $\bullet$ Fácil transformação de coordenadas. & $\bullet$ Fácil manipulação de atributos. \\
& $\bullet$ Representação precisa de objetos. & $\bullet$ Aplicabilidade de analises e \\
& $\bullet$ Representação gráfica eficiente em & & filtragens variadas. \\
& todas as escalas. & $\bullet$ & Fácil modelagem matemática.
\end{tabular}

Tabela 3 - Vantagens e desvantagens das representações de dados. Conclusão.

\begin{tabular}{|c|c|c|}
\hline TIPO & VETORIAL & MATRICIAL \\
\hline & $\begin{array}{l}\text { - Possibilidade de recuperação, } \\
\text { atualização e generalização de dados. }\end{array}$ & $\begin{array}{l}\text { - Várias formas de dados } \\
\text { disponíveis. } \\
\text { - } \begin{array}{l}\text { Melhor representação } \\
\text { fenômenos contínuos }\end{array} \\
\end{array}$ \\
\hline DESVANTAGENS & $\begin{array}{l}\text { - Estrutura complexa. } \\
\text { - Combinação de polígonos requer } \\
\text { grande capacidade de processamento. } \\
\text { - Exibição e impressão podem } \\
\text { consumir muito tempo e ser caras. } \\
\text { - Necessidade de dados extras para } \\
\text { análise de polígonos. }\end{array}$ & 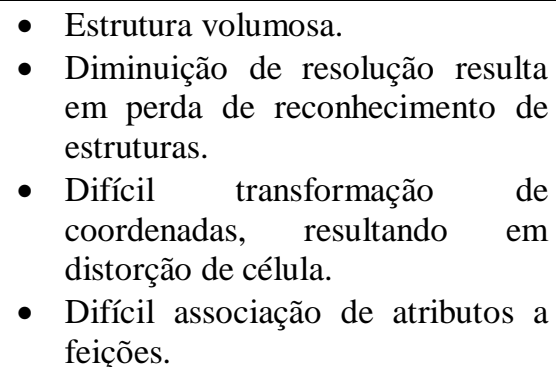 \\
\hline
\end{tabular}

Fonte: Carvalho et al. (2000); Rizzi (2005).

\section{FISIOGRAFIA DA ÁREA ESTUDADA}

O município de Canãa do Carajás (Figura 4) pertence à mesorregião Sudeste Paraense e a microrregião Parauapebas, com uma extensão territorial de $3.146,407 \mathrm{~km}^{2}$ com coordenadas geográficas $6^{\circ} 29^{\prime} 51^{\prime \prime} \mathrm{Sul}, 49^{\circ} 52^{\prime} 42^{\prime \prime}$ Oeste e altitude $286 \mathrm{~m}$. O município é limitado ao Norte por Parauapebas, a Leste por Curionópolis e Sapucaia, ao Sul por Água Azul do Norte e a Oeste por Parauapebas (PARÁ, 2012).

Figura 4 - Mapa de localização do município de Canaã dos Carajás.

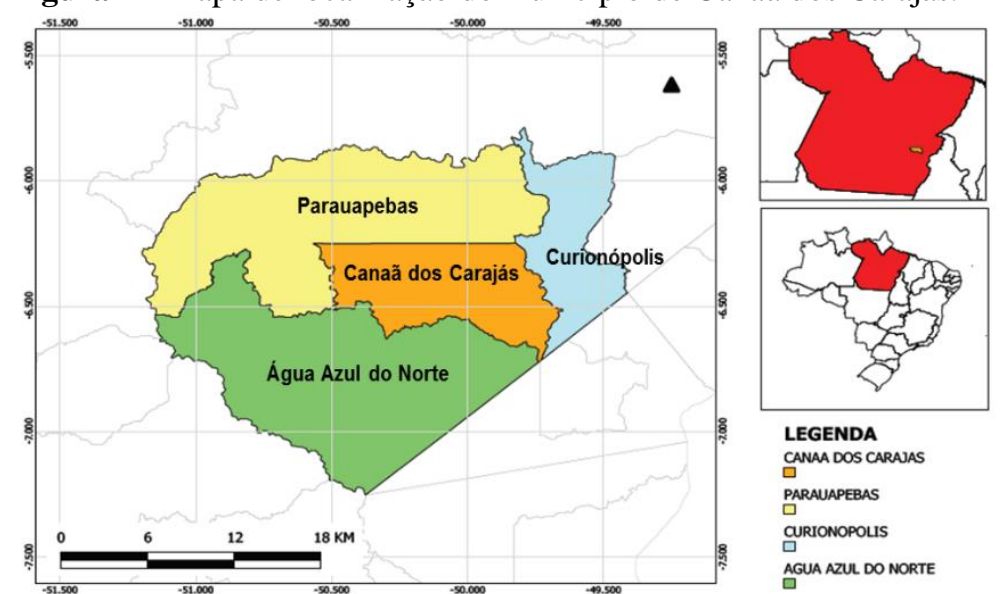


Elaborado pelos autores a partir de dados obtidos no site do IBGE.

\section{HISTÓRICO}

O Município de Canaã dos Carajás teve origem a partir de um assentamento agrícola, o Projeto de Assentamento Carajás, implantado a partir de 1982 pelo Grupo Executivo das Terras do Araguaia e Tocantins (GETAT), do Governo Federal, com objetivo de atenuar conflitos pela posse da terra na região, que ficou conhecida como Centro de Desenvolvimento Regional (CEDERE). Em 1985, as atividades de assentamento terminam e o GETAT foi extinto. Só em outubro de 1994, através da Lei Estadual 5.860, o CEDERE é desmembrado de Parauapebas e vira município de Canaã dos Carajás. A população estimada em 2012 era de 29.101 habitantes (IBGE, 2013).

Quanto classificação do clima, ele é do tipo Tropical úmido com inverno seco, tipo Aw na classificação de Köppen, com variação anual da temperatura do ar de $25^{\circ}$ a $26^{\circ} \mathrm{C}$ (máxima de $31^{\circ}$ a $32^{\circ} \mathrm{C}$, e mínima de $20^{\circ}$ a $21^{\circ} \mathrm{C}$ ). O período mais chuvoso é de novembro a abril, com 100 a 150 dias de chuva, e precipitação anual de 1750 a $2250 \mathrm{~mm}$ (BRASIL, 2006). Em relação a cobertura vegetal, ela é bastante diversificada no município de Canaã dos Carajás, predomina, entretanto, a Floresta Ombrófila Aberta Submontana e a Floresta Ombrófila Densa Submontana (IBGE, 2008).

Na região ocorrem, principalmente, dois tipos de solos (CARVALHO, 2006):

(1) Latossolo vermelho-amarelo: Ocorre com expressividade no Noroeste, Sudeste e Sudoeste do Estado. A fertilidade, assim como a saturação de bases, é geralmente baixa. A textura se apresenta bastante variável.

(2) Podzólico Vermelho-amarelo: São relativamente profundos, férteis, bem drenados, normalmente acidificados, com textura variando de média à argilosal. São muito propícios à erosão e pode ser encontrado no Estado de forma pulverizada na parte Nordeste, Sudeste, Sul e no Baixo Amazonas.

Em relação ao relevo, este, é composto pela depressão da Amazônia meridional seguido de planaltos residuais do sul da Amazônia e pelas serras do sul do Pará (IBGE, 2006). Já a hidrografia, Canaã do Carajás faz parte da Sub-Região Hidrográfica do Itacaiúnas localizada na região hidrográfica do Tocantins-Araguaia que ocupa 10,4\% da área do estado e A precipitação média é da ordem de $1.869 \mathrm{~mm} /$ ano chegando a $2.565 \mathrm{~mm} /$ ano no litoral. A vazão é de $11.800 \mathrm{~m}^{3} / \mathrm{s}$, fornece uma vazão específica média de $15,6 \mathrm{~L} / \mathrm{s} \cdot \mathrm{km}^{2}$. A evapotranspiração real média é de $1.200 \mathrm{~mm} / \mathrm{ano}$ e o coeficiente médio de escoamento superficial é de aproximadamente 0,30 (). Quanto à região hidrográfica é constituída pelas bacias dos rios Tocantins, Itacaiúnas e Araguaia e tem como principais drenagens os rios de mesmo nome, e ainda os rios Preto, Jacundá, Oeiras, Inajá, Gameleira ou Chicão, Salobo, Itacaiunas, Madeira, Parauapebas, Sereno, Sororó, Praia Alta e Trocará (BRASIL, 2007; SEMA, 2007).

O uso e ocupação do solo ocorrem por extrativismo vegetal em área florestal, pecuária de animais de grande porte e mineração de minerais metálicos como, por exemplo, ouro (Au) e cobre $(\mathrm{Cu})$, seja por garimpos não mecanizados, semi-mecanizados ou mecanizados (IBGE, 2011).

\section{RESULTADOS E DISCUSSÃO}


Os dados obtidos e analisados indicaram que houve, no intervalo de quatro anos, (Início em 1984 e finalizado em 2004), uma tendência evolutiva nos valores da área total desflorestada. Isso ocorreu devido a emancipação do município (Tabela 3).

\begin{tabular}{ccccc}
$\begin{array}{c}\text { Tabela } 4 \\
\text { Ano }\end{array}$ & $\begin{array}{l}\text { Avanço do desflorestamento no município de Canaã dos Carajás - PA. } \\
\text { Desflorestamento }\end{array}$ & $\begin{array}{l}\text { Variação de } \\
\left.\text { desflorestamento } \mathbf{( k m}^{2}\right)\end{array}$ & $\begin{array}{c}\text { \% do município } \\
\text { desflorestado }\end{array}$ \\
\hline 1984 & 377,94 & & - & 12,01 \\
1988 & 963,46 & 585,52 & 30,62 \\
1992 & 1409,69 & 446,23 & 44,81 \\
1996 & 1558,44 & 148,75 & 49,54 \\
2000 & 1609,18 & 50,74 & 51,15 \\
2004 & 1713,08 & 103,9 & 54,45 \\
2008 & 1670,53 & $-42,55$ & 53,10 \\
2012 & 1623,89 & $-46,64$ & 51,62 \\
\hline
\end{tabular}

Fonte: IBGE (2008).

Em consequência dessa tendência, houve um aumento das atividades econômicas, pois, em 1988, o percentual alcançou 32,92\% e, em 2004, elevou-se para 59,04\%. Já nos intervalos sequentes (2004 a 2012). Em 2012, houve tendência a redução na área total desflorestada devido a implementação de ações de reflorestamento e atividades de Educação Ambiental (EA) no município desenvolvidas pela mineradora. Essas ações recompuseram 59,04\% \%. Do que foi desflorestado.

\section{4}

A primeira caracterização cartográfica gerada utilizando o software QGIS para realizar a demarcação das áreas desflorestadas do município de Canaã dos Carajás foi feita utilizando uma imagem de satélite do município no ano de 1984 (Figura 5).

Figura 5 - Caracterização Cartográfica da área desflorestada em 1984. Canaã dos Carajás - PA.

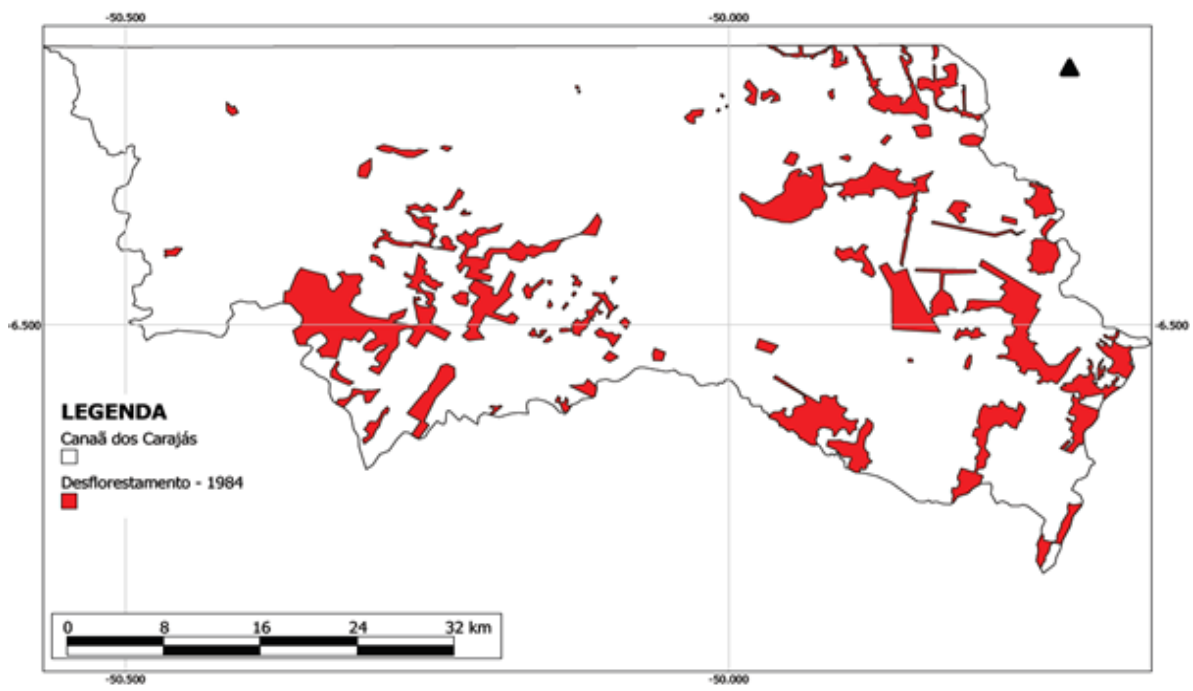

Elaborado pelos autores a partir dos dados obtidos no link eletrônico do LandSat 5

Os cálculos mostraram que a área desflorestada é equivalente a 377,94 km² e 12,01\% da área total do município, com maior abrangência no sentido sudeste, no qual estão localizados os municípios de Xinguara, Curionópolis, Sapucaia e parte de Água Azul do Norte. É valido ressaltar que nesse ano, a área ainda não tinha sido desmembrada do município de Parauapebas e, por isso, não era considerado um município, e sim apenas um assentamento oriundo dos incentivos dos grandes projetos de ocupação da Amazônia. As atividades econômicas desenvolvidas na área nesse período 
eram as mesmas realizadas em projetos de assentamento, agricultura e pecuária, bem como a extração madeireira, devido à ausência de dados quantitativos estas atividades podem ser consideradas como as principais causas do desflorestamento.

\section{A 1988}

A segunda caracterização cartográfica gerada corresponde ao intervalo de quatro anos em relação à ano base, 1984 e estende-se até 1988 (Figura 6).

Figura 6 - Caracterização Cartográfica da área desflorestada de 1994 a 1998. Canaã dos Carajás - PA.

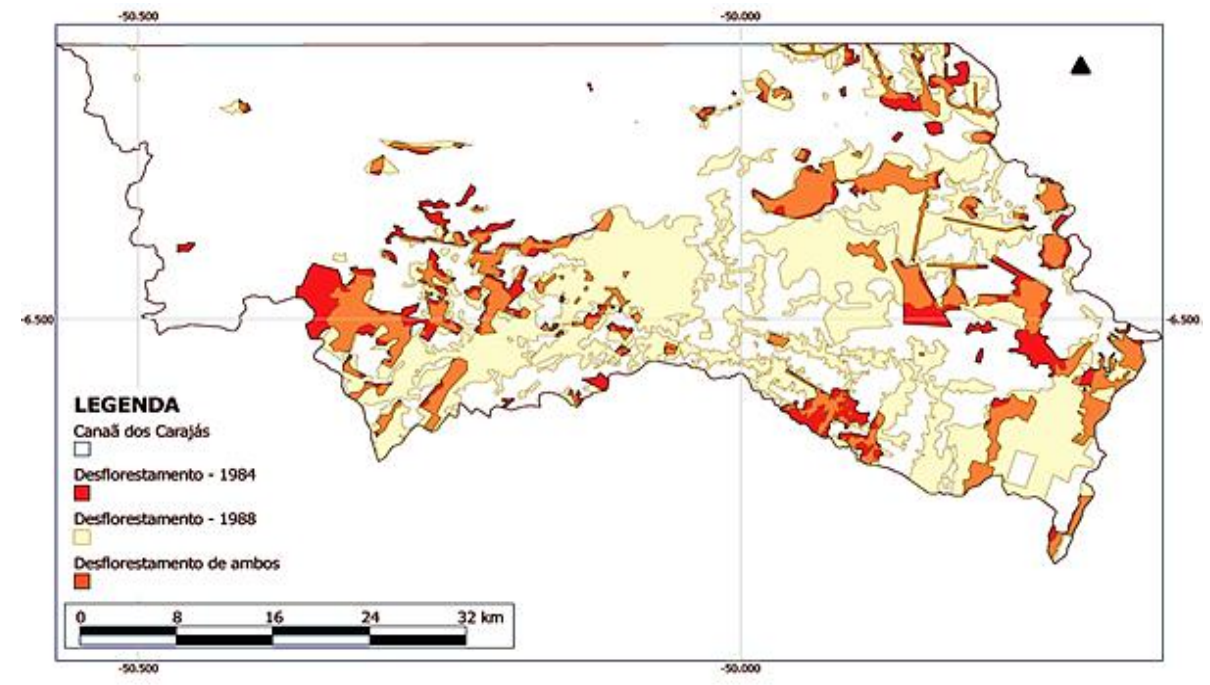

Elaborado pelos autores a partir dos dados obtidos no link eletrônico do LandSat 5

Os dados obtidos indicaram um valor igual a $963,46 \mathrm{~km}^{2}$ (30,62\% da área total do município), e isso significa um aumento de $585,52 \mathrm{~km}^{2}$ em relação ao ano anterior, ou seja, aproximadamente $120 \%$ de crescimento. Com abrangência mais uniforme, a área desflorestada expandiu em direção ao oeste, e criou uma grande região sem vegetação ou com vegetação escassa e esparsa, o que proporcionou a fragmentação florestal. Nesse ano, a área era ocupada pelo Projeto de Assentamento Carajás, porém com maior infraestrutura do que na análise anterior devido à abertura de estradas e pequenos indícios de vilas.

Figura 7 - Caracterização Cartográfica da área desflorestada - Canaã dos Carajás - 1992.

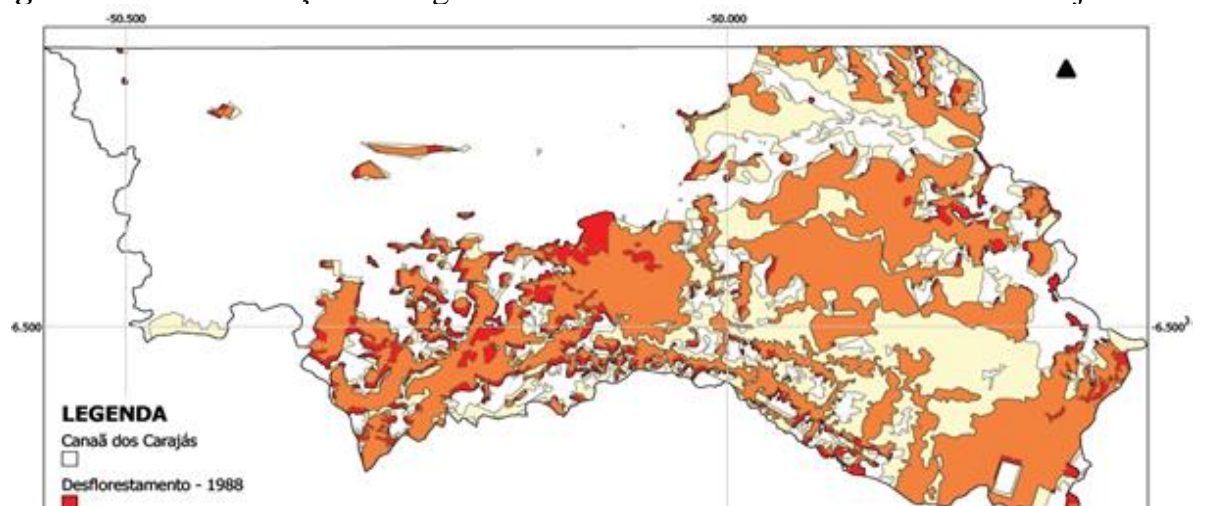


Houve expansão da área desflorestada que, nesse ano, atingiu 1409,68 $\mathrm{km}^{2}$, equivalente a $44,81 \%$ da área total do município e com uma variação de 446,23 km² em relação ao ano anterior, porém, manteve a proporção crescente do desflorestamento.

A área desflorestada manteve-se sem grandes avanços em qualquer direção, em relação aos pontos geográficos como ficaram comprovados nos anos posteriores, porém, notou-se menor densidade de áreas verdes remanescentes na região da borda leste da área, que posteriormente irá se tornar a sede do município. Pôde ser notada uma melhora na infraestrutura com ampliação de estradas e aumento da área das vilas já existentes.

Acredita-se que esta redução nos valores do desflorestamento sejam reflexos da conferência Eco 92, realizada no Rio de Janeiro no mês de Junho de 1992, em que foram debatidas as causas ambientais a nível global e foi criada a agenda 21, com sugestões de práticas que promovam o desenvolvimento sustentável, exercendo uma possível intervenção nas atividades desflorestadoras do município, além das políticas públicas como a Política Nacional do Meio Ambiente através da lei 6938/81, com fundamento nos incisos VI e VII do art. 23 e no art. 235 da Constituição Federal brasileira.

\section{A 1996}

Para esse período, a caracterização cartográfica foi elaborada no quadriênio iniciado em 1992 e encerrou em 1996 (Figura 8).

Figura 8 - Caracterização Cartográfica da área desflorestada no período de 1992 a 1996. Canaã dos Carajás - PA.

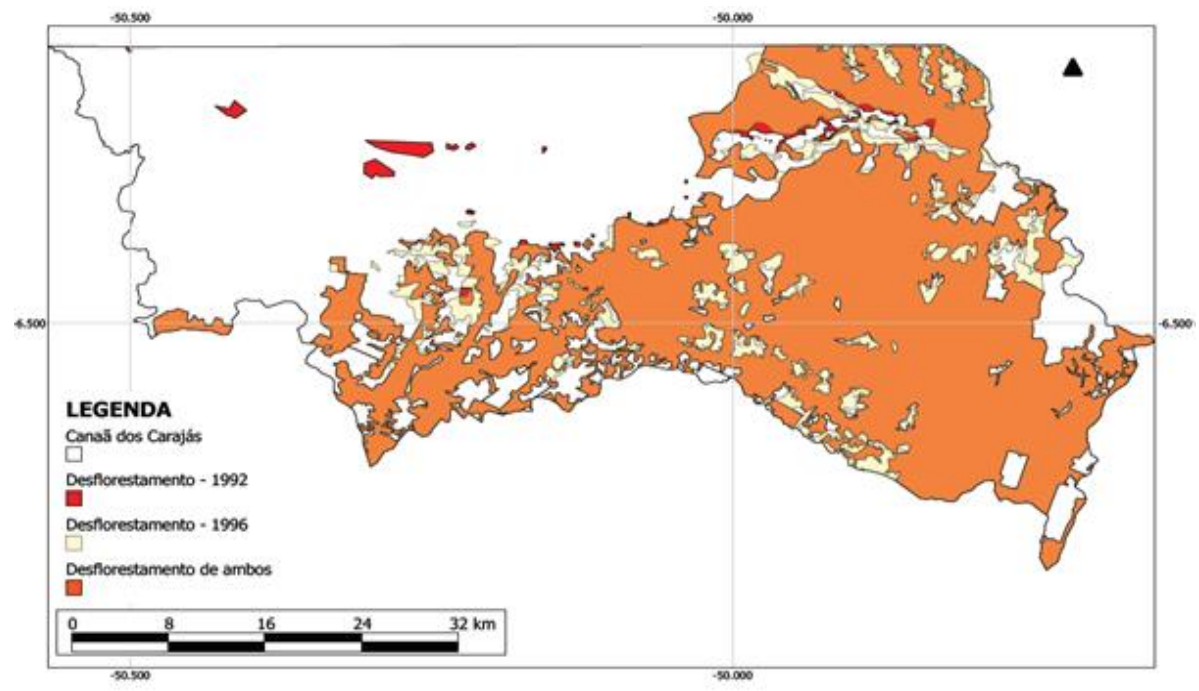

Elaborado pelos autores a partir dos dados obtidos no link eletrônico do LandSat 5 
Os cálculos mostraram um valor igual a $1558,44 \mathrm{~km}^{2}$ de área desflorestada, o equivalente a $49,54 \%$ da área total do município, o que gerou uma variação de $148,75 \mathrm{~km}^{2}$ em relação a análise anterior, sendo a menor e bem abaixo das demais analisadas anteriormente. A área desflorestada continuou a crescer, porém, com valores reduzidos e caracterizado por pequenos avanços em direção ao centro da área, ocasionando uma homogeneidade no que tange a área desflorestada central. No ano de 1994, houve a emancipação do assentamento, tornando-o finalmente o município de Canaã dos Carajás.

\section{A 2000}

A caracterização cartográfica do período seguinte, ou seja, 1996 a 2000, permitiu uma visualização mais adequada do desflorestamento no município pesquisado (Figura 9).

Figura 9 - Caracterização cartográfica da área desflorestada no período compreendido entre 1996 e 2000. Canaã dos Carajás - PA.

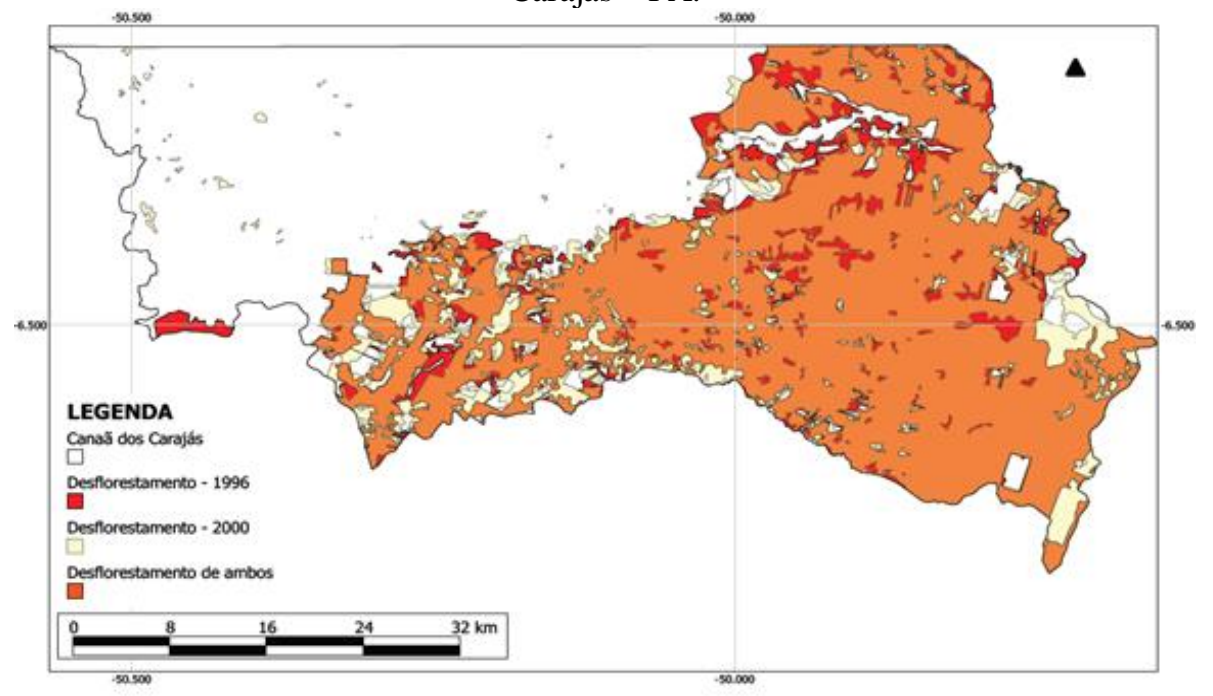

Elaborado pelos autores a partir dos dados obtidos no link eletrônico do LandSat 5

A análise dos dados obtidos indicou um valor igual a $1609,18 \mathrm{~km}^{2}$, o equivalente a $51,15 \%$ da área total do município. Entretanto, este ano apresentou tendência a redução de, aproximadamente, $66 \%$ quando comparado a 1996, pois, neste ano, o houve indicação de incremento de $82,25 \mathrm{~km}^{2}$ no intervalo entre 1996 e 2000.

Nesse contexto, dados publicados pelo IBGE, o Produto Interno Bruto (PIB) do município de Canaã dos Carajás, equivaleu a $\mathrm{R} \$ 27.757$, onde, $\mathrm{R} \$ 14.563$ provenientes da agropecuária, $\mathrm{R} \$ 1.215$ da indústria e R $\$ 10.675$ de serviços diversos. Os valores disponibilizados pelo IBGE só abrangem o período 2000 - 2010. Vale destacar que em 1998, foi publicado o Decreto n. 2.486 de 2 de fevereiro de 1998 que homologou legalmente a Floresta Nacional (FLONA) de Carajás.

\section{A 2004} 10).

A caracterização cartográfica do período seguinte, variação entre os anos 2000 e 2004 (Figura

Figura 10 - Caracterização cartográfica da área desflorestada entre 2002 e 2004. Canaã dos Carajás - PA. 


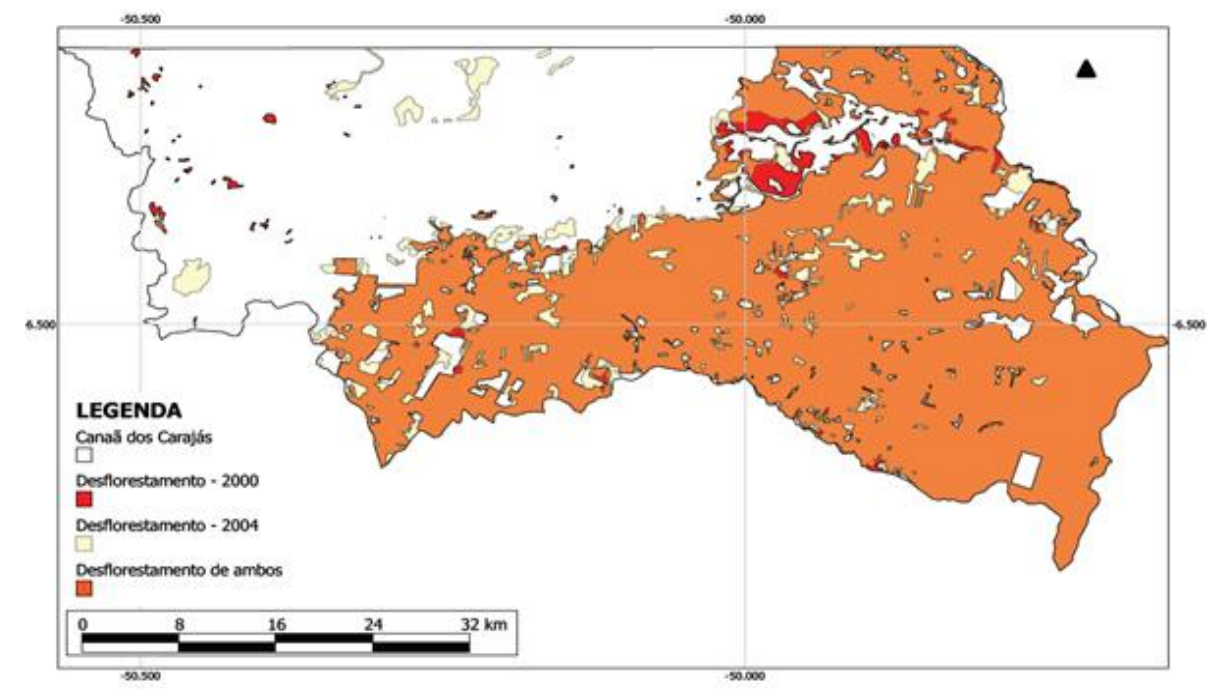

Elaborado pelos autores a partir dos dados obtidos no link eletrônico do LandSat 5

O ano de 2004 apresentou os maiores valores de desflorestamento no município durante o período estudado. Neste ano a área total desflorestada equivaleu a 1713,08 $\mathrm{Km}^{2}, 54,45 \%$ da área total do município, porém, os valores de variação, mesmo elevados em comparação aos valores do período anterior, não apresentaram a mesma intensidade em relação aos períodos anteriormente analisados nesse estudo.

Quanto a este aumento, pode-se inferir que foi em decorrência da implantação da mineradora pertencente ao grupo VALE, atuando no município através do Projeto Ferro Carajás em 2002, pois a implantação e a operacionalidade apresentam atividades desflorestadoras, sejam ela diretas ou indiretas, como a ocupação de áreas não urbanizadas do município.

\section{A 2008}

Para que haja mais assertiva na elaboração da caracterização cartográfica desse ano, sobrepuseram-se as imagens já geradas, ou seja, de 2004 a 2008 (Figura 11).

Figura 11 - Caracterização cartográfica da área desflorestada de 2004 a 2008. Canaã dos Carajás - PA.

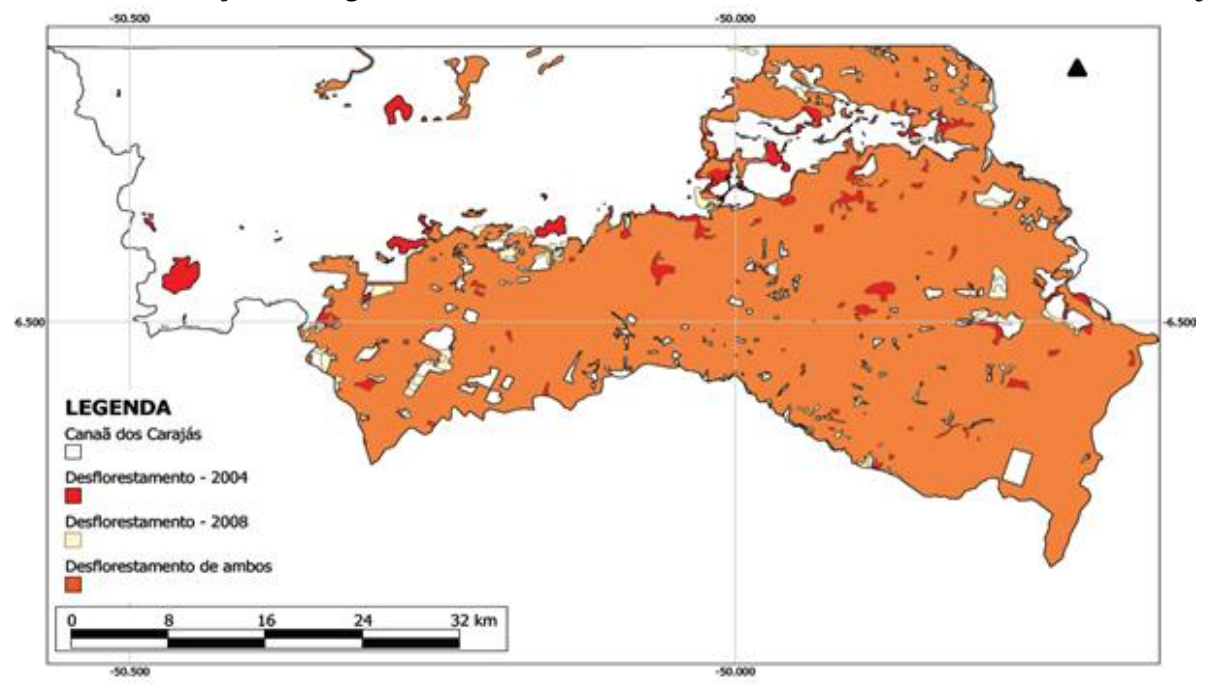


Os valores desse ano trazem uma alteração no padrão de aumento do desflorestamento, e um incremento no processo inverso, ou seja, aumento de área florestada do município, $1670,53 \mathrm{~km}^{2}$, o que equivale a $53,10 \%$, e a redução das áreas desflorestadas representou $42,55 \mathrm{~km}^{2}$ da área total do município.

Acredita-se que a justificativa para estes valores crescente em áreas florestadas são reflexo principalmente de dois fatores: aumento na fiscalização e controle do desflorestamento devido a presença da mineradora e sua ação de programas de reflorestamento como medida ambiental compensatória e da FLONA de Canaã dos Carajás.

A FLONA é uma Unidade de Conservação (UC) Federal gerida pelo Instituto Chico Mendes de Conservação da Biodiversidade (ICMBIO). Esta UC abrange os municípios de Parauapebas, Canaã dos Carajás e Água Azul do Norte e possui área de aproximadamente $392.725,14$ km², ocupando 1.190,90 km² do município de Canaã dos Carajás (Figura 12).

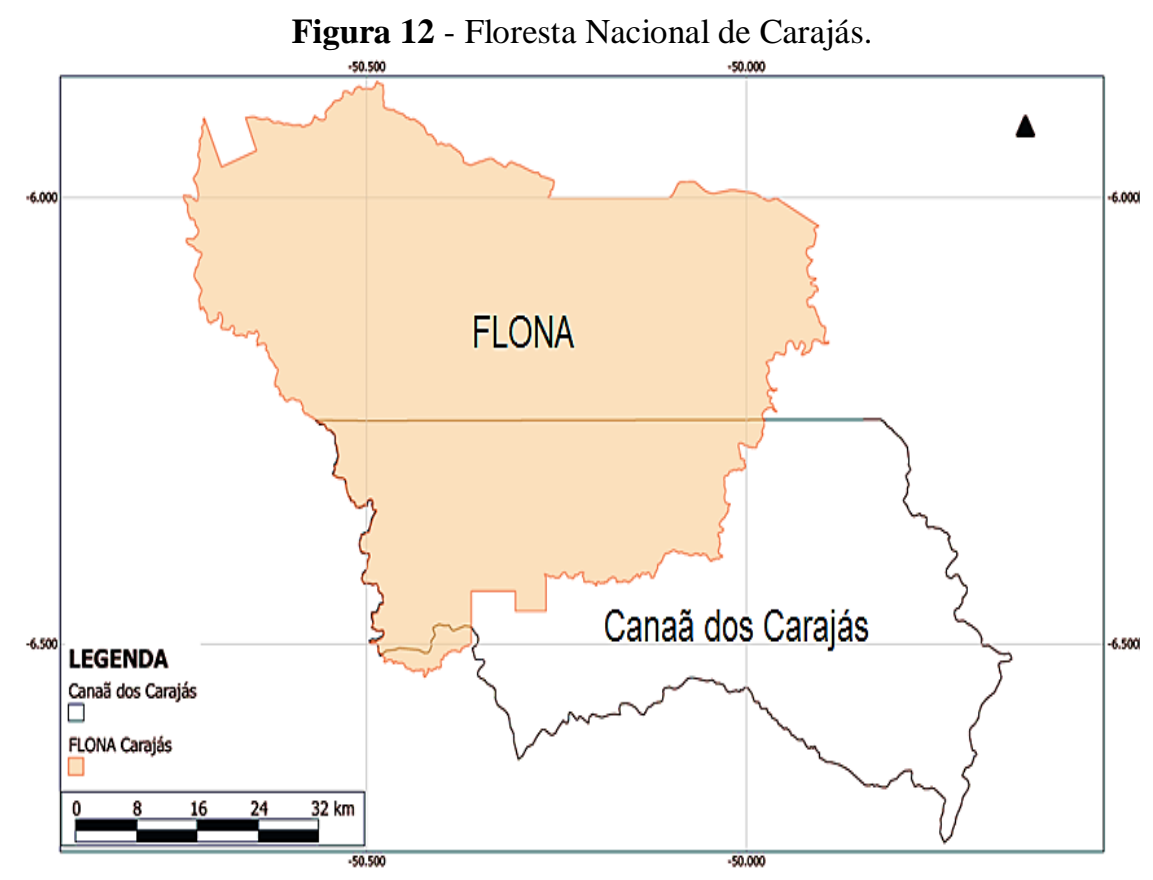

Elaborado pelos autores a partir dos dados obtidos no link eletrônico do LandSat 5

Sendo a área constituída de floresta ombrófila, semi-caducifolia e campos rupestres rodeada por pastagens. Na prática este é um grande refúgio para a vida silvestre e grande testemunho da floresta nativa da região conhecida como "Polígono dos Castanhais" (GUMIER-COSTA; SPERBER, 2009).

2008 A 2012

A caracterização cartográfica do período seguinte, fez-se um mosaico das imagens geradas desde 2008 até 2012, para verificação do crescimento/estagnação do desflorestamento (Figura 13). 
Figura 13 - Caracterização cartográfica da área desflorestada no período de 2008 a 2012. Canaã dos Carajás - PA.

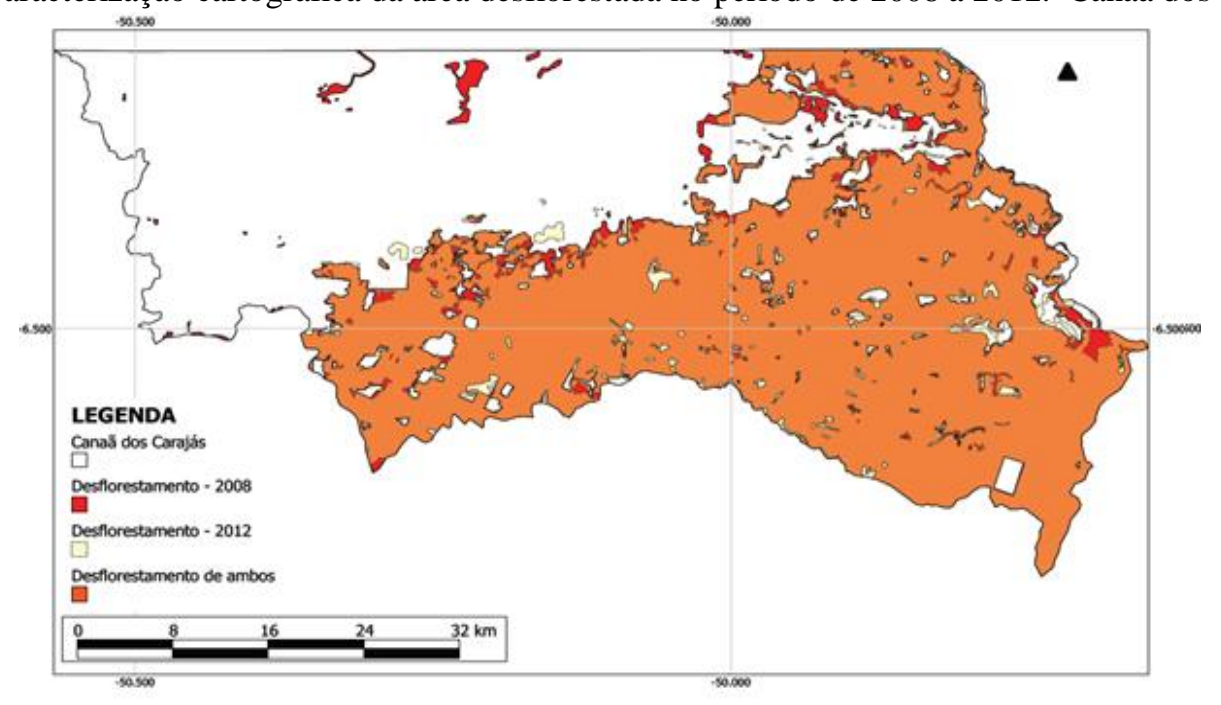

Elaborado pelos autores a partir dos dados obtidos no link eletrônico do Landsat 5

Durante o último ano estudado os valores continuaram apresentando quedas nas taxas de desflorestamento, reduzindo nesse intervalo $46,64 \mathrm{~km}^{2}$ da área desflorestada do município, agora com $1623,89 \mathrm{~km}^{2}$ representando aproximadamente $51,62 \%$ da área total do município, pouco mais que a metade de sua área total. Os valores, entretanto, seguem a mesma linha do último período estudado, e cresceram ainda mais, apesar de não apresentarem a mesma intensidade que os valores de 2004 e 2008.

De maneira geral, analisaram-se as imagens, e verificou-se grande o avanço da área desflorestada durante o período 1984-1988, e menor avanço entre 2008 - 2012, apresentando os maiores valores para área desflorestada total no município o ano de 2004 (Figura 14).

Figura 14 - Valores para o desflorestamento: 1984 a 2012. Canaã dos Carajás - PA.

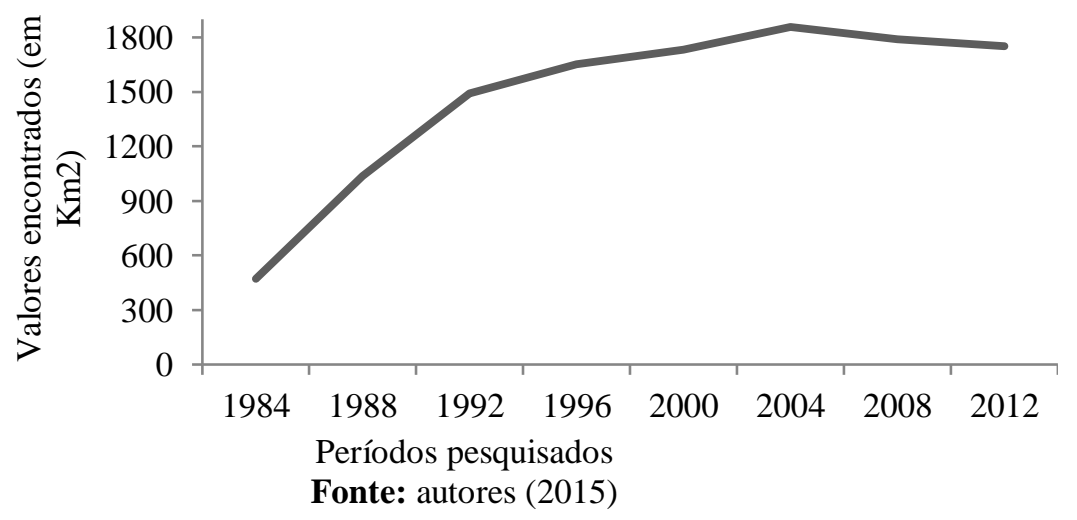

Percebeu-se também que a área florestada do município corresponde a aproximadamente a área que não faz parte da FLONA, serve como uma espécie de limite, demarcando o avanço da área urbana. O desflorestamento no município de Canaã dos Carajás durante 1984 e 2012 apresentou valores e variações condizentes com as informações presentes na literatura, tal relação pode ser vista nos primeiros anos de estudo, através da influência das políticas públicas no avanço da fronteira urbana.

Na década de 80 data os primeiros anos do estudo e os últimos anos da participação direta das políticas públicas, que apresentaram os maiores valores de variação de desflorestamento entre os períodos de 1984 -1986 e 1986 -1988, já que neste período ainda existiam características de expansão 
de fronteira e integração nas áreas de Projeto de Assentamento. O planejamento na região passou a ampliar a ação militar e a concentrar recursos em pequenas áreas de grande extensão, que é o caso do Projeto Ferro Carajás, atuante no município estudado (BECKER, 2005).

A região pertencente à Amazônica Legal Brasileira, na qual está incluída a região Sudeste do Pará, passou por um conjunto de políticas governamentais e ações da sociedade civil entre 2007 e 2010, estas políticas contribuíram para a redução do desflorestamento no município e aliaram criação de Áreas Protegidas, restrições financeiras e comerciais contra agentes desflorestadores e controle tradicional, que inclui multas, apreensões de bens e produtos de origem ilegal (OLIVEIRA JUNIOR; CARVALHO JÚNIOR, 2013).

\section{CONCLUSÕES}

Houve grande avanço da área desflorestada com maior intensidade durante o período iniciado em 1984 e estende-se até 1988, período em que o avanço foi fomentado pelos grandes projetos citados, período este que seguiu apresentando o maior valor de desflorestamento no ano de 2004 e os menores nos anos de 2008 a 2012, havendo, inclusive, uma redução da área.

Percebe-se também que a área florestada do município corresponde a aproximadamente a área que faz parte da FLONA de Carajás, o que limita o avanço da área urbana e é uma demonstração clara que a legislação, aliada ao monitoramento, inibe o avanço do desflorestamento em toda e qualquer área.

Com relação às geotecnologias, pode se afirmar que, aliada ao uso de satélites, são atualmente de grandiosa importância para a manutenção das florestas pois possuem qualidades como a relativa facilidade de manuseio, banco de dados constantemente alimentados e gratuitos, ampla rede de comunicação mundial, rápidas respostas, correlacionamento de dados e saídas de dados multiforme.

A partir destes resultados nota-se que o uso das geotecnologias, aliado às legislações inerentes às causas ambientais pode alcançar valores significativos de redução da intensidade das atividades desflorestadoras, em casos como o de Canaã dos Carajás estas ações foram além, reduzindo a área desflorestada no município. A grande dificuldade continua sendo a sensibilização da sociedade, e a carência de uma efetiva educação ambiental bem difundida entre os atores sociais, porém, já é possível identificar sinais de uma mudança, seja ela decorrente de uma nova mentalidade ou pela interferência de caráter punitivo advinda da legislação.

\section{REFERÊNCIAS}

ABDON, M. M. Os impactos ambientais no meio físico - erosão e assoreamento na bacia hidrográfico do rio taquari, MS, em decorrência da pecuária. 2004. Tese (Doutorado Engenharia Ambiental). Escola de Engenharia de São Carlos. Universidade de São Carlos, São Carlos, 2004.

ALMEIDA, S. et al. O desmatamento na Amazônia e a importância das áreas protegidas. Estudos avançados. São Paulo v.19, n.53, jan. lapr. 2005. Disponivel em: <http://www.scielo.br/scielo.php?pid=S010340142005000100010\&script=sci_arttext\&tlng=pt> Acesso: 10 jul. 2013.

BECKER, B. K. Revisão das políticas de ocupação da Amazônia: é possível identificar modelos para projetar cenários? Modelos e cenários para a Amazônia: o papel da ciência. PARCERIAS ESTRATÉGICAS, $12.2001 . \quad$ n. 12 Disponível <http://www.ufpa.br/epdir/images/docs/paper28.pdf>. Acesso em: 22 nov. 2013

BRASIL. Banco Mundial. Causas do Desmatamento da Amazônia Brasileira. Brasília 2003. 100 p. Disponível em: <http://siteresources.worldbank.org/BRAZILINPOREXTN/Resources/3817166- 
1185895645304/4044168-1185895685298/010CausasDesmatamentoAmazoniaBrasileira.pdf> acesso em: 09 jul. 2013.

BRASIL. Caderno Regional Da Região Hidrográfica Do Tocantins-Araguaia. 2006. Ministério do Meio Ambiente. Programa de estruturação institucional para a consolidação da Política Nacional de Recursos Hídricos - BRA/OEA/01/002. Relatório final, Brasília, 2006.

BRASIL. Agência Nacional de Águas. A Navegação Interior e sua Interface com o Setor de Recursos Hídricos no Brasil e Aproveitamento do Potencial Hidráulico para Geração de Energia no Brasil/Agência Nacional de Águas, Brasília: Superintendência de Planejamento de Recursos Hídricos, 2007.

CÂMARA, G.; DAVIS, C.; MONTEIRO, A. M. V. Introdução à Ciência da Geoinformação. São José dos Campos. 2001. Disponível em: http://www.dpi.inpe.br/gilberto/livro/introd/index.html. Acesso: 10 jul. 2013.

CARVALHO, M. S. Manual de reflorestamento. Belém. 2006. Disponível em: http://geomaurotorres.blogspot.com.br/2009/06/principais-tipos-de-solos-do-estado-do.html. Acesso: 10 jul. 2013.

CARVALHO, M. S. et al. Conceitos básicos de sistema de informação geográfica e cartografia aplicados à saúde. Brasília: Organização pan-americana de saúde/ Ministério da Saúde. 2000.

FEARNSIDE, P. M. Desmatamento na Amazônia brasileira: história, índices e consequências. Revista Megadiversidade, v.1, n. 1, p. 113-123, jul. 2005.

FELGUEIRAS, C. A. A tecnologia SPRING, breve histórico, status atual e evolução. Anais $1^{\circ}$ Simpósio de Geotecnologias no Pantanal, Campo Grande, Brasil, 11-15 novembro 2006, Embrapa Informática Agropecuária/INPE, p.811-824. Disponível em:

http://mtcm17.sid.inpe.br/col/sid.inpe.br/mtcm17\%4080/2006/12.08.13.39/doc/p145.pdf. Acesso em: 10 jul. 2013.

FERREIRA, C. N. Apostila de sistema de informações geográficas. Centro Federal de Educação Tecnológica de Goiás. Goiânia. 2006.

Disponível

em: http://www.geolab.faed.udesc.br/sites_disciplinas/geoprocessamento_aplicado_ao_planejamento/do cs/apostila_sig\%5B1\%5D.pdf. Acesso em: 10 jul. 2013.

FERREIRA, L. V.; et al. O desmatamento na Amazônia e a importância das áreas protegidas. Estudos Avançados, v.19, n.53, p. 157 - 166, jan./ apr. 2005

FIGUEROA, S. N.; NOBRE, C. A. A New Precipitation distribution over Tropical South America West of 40W. Centro de Previsão do Tempo e Estudos Climáticos (CPTEC). Instituto de Pesquisas Espaciais (INPE). 1990. Disponível em: http://www.cbmet.com/cbm-files/18d169fc5e7fa05ed58f6bcbb3013c1efc.pdf. Acesso em: 22 nov. 2013

FISCH, G. et al. Simulações climáticas do efeito do desmatamento na região amazônica: estudo de um caso em Rondônia. Revista Brasileira de Meteorologia, v. 12, n. 1, p.33-48. 1997.

GIROTTO, J. Desenvolvimento de sistema computacional utilizando geotecnologias aplicadas a roteirização da entrega de cargas. Santa Maria, RS. 2011. Disponível em: 
http://cascavel.cpd.ufsm.br/tede/tde_arquivos/21/TDE-2011-09-13T173221Z-

3206/Publico/GIROTTO,\%20JUNIOR.pdf. Acesso: 10 jul. 2013.

GUMIER-COSTA, F; SPERBER, C. F. Atropelamentos de vertebrados na Floresta Nacional de Carajás, Pará, Brasil. Acta Amazonica, v. 39, n.2, p. 459 - 466. 2009.

HOREL, J. H.; HAHMANN, A. N.; GEISLER, J. E. An investigation of the annual cycle of convective activity over the tropical Americas. Journal of Climate, v. 2, n.11, p. 1388-1403, 1989.

IBGE. INSTITUTO BRASILEIRO DE GEOGRAFIA E ESTATÍSTICA. Mapa de vegetação. 2008. Disponível em:

ftp://geoftp.ibge.gov.br/mapas tematicos/vegetacao/unidades_federacao/pa_vegetacao.pdf. Acesso em: 10 jul. 2013.

IBGE. INSTITUTO BRASILEIRO DE GEOGRAFIA E ESTATÍSTICA. Histórico do Município de Canaã dos Carajás. $2006 . \quad$ Disponível em:< http://www.ibge.gov.br/cidadesat/painel/painel.php?codmun=150215\&search=para|canaa-doscarajas\#historico> Acesso em: 10 jul. 2013.

IBGE. INSTITUTO BRASILEIRO DE GEOGRAFIA E ESTATÍSTICA. MAPA de uso do solo. 2011. Disponível em:< ftp://geoftp.ibge.gov.br/mapas_tematicos/uso_da_terra/unidades_federacao/pa_uso.pdf $>$ Acesso em: 10 jul. 2013.

LIMA, A. Caracterização do padrão temporal de regeneração florestal da Amazônia oriental em áreas desmatadas no ano de 2001. XV Simpósio Brasileiro de Sensoriamento Remoto - SBSR, Curitiba, PR, Brasil, INPE p.6161. 2011.

MATIAS, L. F. Sistema de informações geográficas (SIG): teoria e método para representação do espaço geográfico. Universidade de São Paulo. São Paulo. 2001. Disponível em: http://www.ige.unicamp.br/geoget/acervo/teses/Sistema\%20de\%20Informacoes\%20Lindon.pdf. Acesso em: 10 jul. 2013.

MONTANHER, O. C. Operacionalidade do sistema de informação geográfica - estudo de caso: Spring. Universidade Estadual de Maringá. 2008. Disponível em: <http://www.dge.uem.br/semana/eixo5/trabalho_72.pdf> Acesso em: 10 jul. 2013.

NASCIMENTO, F. I. C.; LIRA, E. M. O uso das geotecnologias como ferramenta para o mapeamento de focos de queimadas na Amazônia Sul-ocidental. REVISTA GEONORTE, v.2, n.4, p.1646 1654. 2012.

OLIVEIRA, F. A reconquista da Amazônia. Novos Estudos, CEBRAP, n. 38, p. 3 -14. 1994.

OLIVEIRA JUNIOR; L. A. L.; CARVALHO JUNIOR; J. G. Modelagem do desmatamento em 30 municípios da região sudeste do Pará. In: XVI SIMPÓSIO BRASILEIRO DE SENSORIAMENTO REMOTO, 16. 2013. Paraná. Anais... Foz do Iguaçu 2013.

PARÁ (Estado). Secretaria de Estado de Planejamento, Orçamento e Finanças. Estatística Municipal: Canaã dos Carajás. Pará, 2012. Disponível em:< http://www.idesp.pa.gov.br/paginas/produtos/EstatisticaMunicipal/pdf/CanaaCarajas.pdf> Acesso: 10 jul. 2013. 
PINTO, P. Software SIG disponíveis para Linux. 2012. Disponível em: http://pplware.sapo.pt/linux/software-sig-disponveis-para-linux. Acesso em: 10 jul. 2013.

PRESTES, M. L. M. A pesquisa e a construção do conhecimento científico: do planejamento aos textos, da escola à academia. 2. ed. São Paulo: Rêspel, 2003.

RIZI, R. Geotecnologias em um sistema de estimativa da produção de soja: estudo de caso no rio grande do sul. INPE. São José dos Campos. 2005. Disponível em: http://www.obt.inpe.br/pgsere/Rizzi-R-2004/publicacao.pdf. Acesso: 10 jul. 2013.

ROSA, R. Geotecnologias na geografia aplicada. USP (SP): Revista do Departamento de Geografia, n 16, p. 81 - 90. 2005.

RODRIGUES, R. L. V. Análise dos Fatores Determinantes do Desflorestamento na Amazônia Legal. Universidade Federal do Rio de Janeiro, Rio de Janeiro: COPPE, 2004.

SEMAS. SECRETARIA DO MEIO AMBIENTE E SUSTENTABILIDADE. 2007. Disponível em: http://www.sema.pa.gov.br/diretorias/recuros-hidricos/gesir. Acesso em: 10 jul. 2013.

SILVA, M. R. Estratégias de conservação da floresta amazônica brasileira: Importância das Unidades Conservação e das Florestas Privadas na Redução do Desmatamento. Universidade Internacional de Andalucia. 2010.2 Disponível em: http://dspace.unia.es/bitstream/10334/767/3/0149_RochadaSilva.pdf. Acesso em: 18 nov. 2013.

SOARES FILHO, B. S. et al. Nexo entre as dimensões socioeconômicas e o desmatamento na Amazônia: a caminho de um modelo integrado. In: BATISTELLA, M.; ALVES, D.; MORAN, E. (Org.). Amazônia. Natureza e Sociedade em Transformação. São Paulo, 2008, v. 1. http://www.csr.ufmg.br/dinamica/publications/cap6.pdf. Acesso em: 26 set. 2013

SOUSA, I. S. Grandes projetos na Amazônia: mudanças e perspectivas na produção do estado urbano em Iranduba - AM. ACTA GEOGRÁFICA, ed. Especial. p. 71 - 80. 2011. Disponível em: https://revista.ufrr.br/actageo/article/viewFile/552/567. Acesso em: 20 nov. 2013.

VALERIANO, D. M. et al. Dimensões do Desmatamento na Amazônia Brasileira.In. Martine, G. População e Sustentabilidade na era das mudanças ambientais Globais: Contribuições para uma Agenda Brasileira. p. 223-238. 2012.

VARGAS, J. et al. $\mathrm{O}$ desmatamento de áreas permanentes e reservas legais em propriedades rurais detectados por geotecnologia: o caso do município de Campo Novo do Parecis-MT. III Simpósio Brasileiro de Ciências Geodésicas e Tecnologias da Informação. Centro de Tecnologia e Geociências - UFPE. Recife, PE. 2010.

VILELA, T. A. Avaliação do Desmatamento e seus Possíveis Impactos nas Mudanças Climáticas da Bacia do Rio Turvo Sujo - MG. Universidade Federal de Viçosa. Minas Gerais. 2009.

Hilquias Miranda Cortez Engenheiro Ambiental. hilquias.cortez@gmail.com 
. samyzin@hotmail.com

Antônio Pereira Júnior Mestre em Ciências Ambentais

Universidade do Estado do Pará

Departamento de Engenharia Ambiental antonio.junior@uepa.br 